\title{
Narrative on How Engineering Leaders Perceive, Learn, and Re-interpret under Resource Constraints - A Case Study of a Rubber Fender Manufacturer in Taiwan
}

\author{
Wei-Shang Fan \\ Kuo-Chung Huang \\ Professor \\ Ping-Yu Chiang \\ Ph.D. Student \\ Associate Professor \\ Department of Business Administration \\ Nanhua University, \\ Chiayi Taiwan
}

\begin{abstract}
Business managers attach great importance to innovation and entrepreneurship, as they are essential to modern organizational, economic, and social development. From specific perspectives, it is challenging to describe details of and gain insights into the process of innovation and entrepreneurship. This paper attempts to observe from an entrepreneurial perspective. It targets a resource-constrained traditional SMB dedicated to producing rubber products in Taiwan. With data collected and organized by narrative inquiry, it analyzes and interprets the narrated history covering a series of innovation actions in three stories, including acquiring the absorptive capacity of knowledge, bricolage, and value-creation. The research reveals insights and implications in the whole history: (1) Self-awareness triggered by difficulties and constraints is the key to initiate knowledge innovation actions; (2) Unique action and learning experiences provide the basis for putting bricolage into practice; and (3) Re-interpretation in multiple contexts helps in value-creation by reforming processes.
\end{abstract}

Keywords: Narrative Inquiry, Absorptive Capacity of Knowledge, Bricolage, Value-Creation

\section{Introduction}

With so many opportunities for innovation and entrepreneurship created by rapid advances in information technology and emerging economic globalization, business management cannot afford to deny the importance of entrepreneurship. However, firms, organizations, or entrepreneurs sometimes may find themselves constrained in terms of resources as they face difficult situations. Some organizations continue to use existing resources to operate and even grow, developing new products and services in anticipation of changing or new market needs, while others do not know how to use their existing and hidden resources. It is in such unpredictable circumstances that bricolage is particularly useful, as it calls on creativity to respond to changes in the environment (Lennerfors \& Rehn 2014).

Small and medium businesses (SMB) are typically resilient and responsive but are widely believed to be weak due to their small size and scarce resources. An, Zhao, Cao, Zhang, \& Liu (2018) suggest that business leaders can identify emerging opportunities through bricolage, which as an active element with a meaningful driving force, can help firms remove resource constraints, and motivate them to stimulate innovation and upgrade strategies to enhance their abilities to weather risks. Besides, SMBs have many hidden or underused resources (Di Domenico, Haugh, \& Tracey 2010). Therefore, business managers must decide and to use appropriate elements through bricolage and execute them swiftly to solve the issues they face (Hsiao, Ou\& Wu 2017; Baker \& Nelson 2005; Garud \& Karnøe 2003). In fact, bricolage can generate various forms of process knowledge, product knowledge, and critical resources. However, without heterogeneous resources and knowledge, high levels of bricolage may also lead to negative effects (Senyard, Baker, Steffens \& Davidsson 2014). Without proper absorption and learning, an individual or organization will not be able to draw value from the information or knowledge transferred in the social network, even with the best channels of knowledge and information (Lin, Liou \& Liu 2007). From the perspective of an entrepreneur, entrepreneurship emerges gradually from the process in which an actor is motivated by many contexts. The focus of relevant research is on the interdependence and interaction between the contexts and relevant elements (Tsai, Shih \& Li 2010). 
It is the issues of not only how a new business entity is established and operated, but also how entrepreneurs can accumulate their actions in everyday living to obtain outcomes (Steyaert 2004).

This paper also adopts the perspective of entrepreneurship. It proposes that actions and contexts should be studied as a whole from the lived experience of actors. Specifically, using the method of narrative inquiry, it attempts to understand the value-creating experience of resource-constrained firms by observing the complex and non-linear aspect of the process holistically.

\section{Literature review}

\subsection{Absorptive capacity of knowledge}

Distinctive resources and capabilities can provide a competitive edge and are indispensable in business competition. However, under changing environments and market uncertainties, the resources and capabilities of a firm may be insufficient to cope with an influx of challenges and constraints. In particular, SMBs that are weak and subject to resource constraints must make the most of their limited resources to remove the constraints (Hsiao, Ou\& Wu 2017). Knowledge is the basis of capabilities that are demonstrated in various dimensions. A firm will be vulnerable to headwinds and threats when its knowledge is insufficient to cope with challenges and constraints. Therefore, an increasing number of firms find that internal bricolage alone is not enough to respond to fast-moving markets. They must manage to acquire external resources to make up their deficiencies (Ou 2015). To maintain and strengthen competitive advantages, the absorptive capacity of knowledge is a critical concept.

The concept is initially framed in the absorptive capacity theory (ACT) in Cohen and Levinthal (1990). In analyzing the role of a firm's research and development (R\&D) activities, they argue that the assimilation of new knowledge can enhance a firm's creativity and flexibility, which in turn gives rise to better performance. From the perspective of capabilities, they suggest that absorptive capacity involves the abilities to recognize and evaluate, assimilate, and utilize information to improve a firm's performance. They also define absorptive capacity as 'the ability of a firm to recognize the value of new, external information, assimilate it, and apply it to commercial ends.' Lin, Liou\& Liu (2007) argue from an organizational perspective that better absorptive capacity enables an organization to obtain a profound understanding and to utilize the acquired new knowledge for leveraging emerging opportunities more swiftly. The intentional inflow and outflow of knowledge can speed up innovative internal activities, while innovative products or services can promote market expansion (Chesbrough 2003). With resources acquired from the outside, a firm can leverage late-mover advantages to change the revenue and profit structures and lead an industrial transformation (Ou 2015). On the other hand, organizations that follow suit may take a long time to keep up with high costs, low speed, and poor results. The key to the difference is the absorptive capacity of knowledge. Therefore, knowledge is fundamental to the operation of resources. Absorption of new, external knowledge based on prior knowledge can enhance a firm's capability for effectively combining and leveraging constrained resources to cope with competition on a daily basis.

\subsection{The concept of bricolage}

French anthropologist Lévi-Strauss (1966) introduces the concept of bricolage with the example of a craftsman, who could use tools or materials at hand in his project or those that are available but irrelevant. He may also retain elements that are not needed at the time but might be needed in the future. Initially, the concept of bricolage is not clearly defined. However, in the field of business management, it is used to explain a special phenomenon related to resources in an organization (Duymedjian\&Rüling 2010; Cunha 2005; Baker \& Nelson 2005). A specific definition of bricolage is also proposed. Cunha (2005), in exploring an organization's resource management activities based on the concept of bricolage, defines it as 'the invention of resources from the available materials to solve unanticipated problems.' Baker \& Nelson (2005) divide bricolage into three attributes: '(1) making do, that is, a bias toward action and active engagement with problems or opportunities rather than lingering over questions of whether a workable outcome can be created,' '(2) combinations of resources for new purposes,' referring 'to the use or reuse of resources in ways other than those for which they were intended,' and (3) using resources at hand, referring to a way of using resources at low cost and without waste, and defined as 'applying combinations of the resources at hand to new problems and opportunities.

Lévi-Strauss (1966) suggests that the logic of bricolage thinking is the science of the concrete. A bricoleur can leverage different thinking logics and gradually combine materials into something with a certain order and structure. The process also involves grouping and arrangement. The key to bricolage is that elements are recognized for future use. That is, these materials are recognized as useful rather than recognized for their usefulness. The first step in bricolage is retrospection. The bricoleur turns back to an already existent set to consider what it contains.

In other words, he reconsiders the resources at hand to explore different uses and functions. The second is archetype bricolage. The structure comprised by many elements is not invariable. It converges to a stable state only after it is 
tested in bricolage (Lévi-Strauss 1966). The structure, which is a combination of events and elements, can be deemed as the basic archetype formed by elements. Any artifact has its structural features, and every constituent has its purposes.

When a resource is separated from its original purpose and is incorporated into another system standing in successive relations to others, it is permutable. The allocation and linkage of resources (Glucksberg \&Danks, 1968; Lévi-Strauss 1966), that is, how resources fit with each other, are also important factors affecting the effectiveness of bricolage. Therefore, the effectiveness of archetype bricolage, that is, the state of the structure, will be affected by the changes to events and targets (Chen, Wu \& Hsiang 2010); the third deals with available resources. Using resources at hand is a key attribute of bricolage, in which existing elements are used as the basis for a combination of resources (Garud\&Karnøe, 2003; Chen, Wu \& Hsiang 2010); these authors argue that for selection of resources, what matters is the availability of resources rather than the abundance and variety of options. Therefore, the availability of resources is the key factor affecting whether a bricoleur can successfully find elements for his project.

\subsection{Value-creation from resources}

'The resource-based view (RBV) has shifted from a focus on describing how companies can achieve sustained profitability by having access to resources that are valuable, rare, inimitable, and nonsubstitutable' 'to focusing on how resources can be combined in order to drive profitability' (Tsai \& Liao 2016; Chesbrough 2010; Kraaijenbrink, Spender, \&Groen 2010). Tsai and Liao (2016) argue that a firm with only distinctive resources cannot sustain its competitive advantages in an environment undergoing rapid and unforeseeable changes (Wilson 2012; Teece 2007; Teece, Pisano, \&Shuen 1997). To integrate internal and external resources effectively is the best way to create dynamic capabilities (Eisenhardt\& Martin 2000; Karim \& Mitchell 2000). The firms that have competitive advantages are those with dynamic capability, 'demonstrating timely responsiveness and rapid and flexible product innovation, along with the management capability to effectively coordinate and redeploy internal and external competences' (Teece 2007; Teece, Pisano, \&Shuen 1997). Both the RBV and the dynamic capabilities view are in essence the belief that resources are critical to an organization's value-creation (Ou 2015). A combination of resources from any products or firms has the chance of creating or presenting diversified types of values (Chen, Wu \& Hsiang 2010; Bowman \&Ambrosini 2000), such as market values (for example, sales revenue, output), social values (for example, culture, aesthetics, social networking, justice), and personal values (for example, learning), etc. (Chen, Wu \& Hsiang 2010). For fully leveraging the potential value of resources and changing their values, the essence of value-creation is the innovative use of resources.

\section{Research method}

\subsection{Narrative inquiry}

Narrative inquiry uses stories to describe and delve into human experiences and actions. It facilitates understanding of the whole history systematically and in context. Gartner (2007) argues that research on entrepreneurship has the most substantial gap in terms of an entrepreneurial narrative. Therefore, the narrative inquiry through storytelling should assume a more significant role in the research field of entrepreneurship. On narrative inquiry, $\mathrm{Chen}, \mathrm{Wu}$ and Hsiang (2010) propose a fundamental hypothesis that there is no single and absolute truth in the real world or any exact reading or interpretation of a text.

Creswell (1998) and Creswell and Clark (2007) argue that for understanding a particular person's living world, a biographical interview requires only one participant. For understanding someone's living story, the narrative interview needs one-three participants. This study analyzes a firm's existing knowledge base by observing how its manager works on a daily basis, to understand how bricolage is carried out given the absorptive capacity of knowledge under resource constraints. As the living and working experience of the interviewee is involved, his living history must be the focus of the study. Therefore, the study adopts a qualitative research method by interpreting the collected data. It focuses on the history of how the actor creates meanings in analyzing complex lived experiences in the story told by the interviewee (Tsai, Shih \& Li 2010).

\subsection{Data collection and organization}

The first step involves the narrator telling or writing down his/her lived experiences without any external influences, including collecting stories from self-descriptions, dialogs, meetings, and interviews (Tsai, Shih \& Li 2010; Clandinin\& Connelly 2000). The collected data are referred to as narrative materials, which are part of the data sources of the study. Interviewing is a method for acquiring data to interpret rather than to obtain facts or principles. Rubin and Rubin (1995) suggest that interviewing is one of the ways to discover and explore the meanings underlying people's living, routines, behaviors, and perceptions. It aims at understanding the interviewee rather than confirming the accuracy of the information. Therefore, it enables the researcher and the interviewee to explore the meanings of their subject matter deeply (Arksey\& Knight, 1999). As shown in Table 1, the second part of the data sources are recordings (obtained by shadowing) about the narrator's daily business operations (Tsai, Shih \& Li 2010). The organization of the data is divided into two stages. 
The first involves the cooperation between the narrator and the researcher for generating field text through interviewing and discussing the narrative materials. In the second stage, the researcher works alone to identify theoretical concepts in the field text. From the theoretical perspectives, the researcher extracts research text with theoretical significances. In interpreting the text, the researcher keeps on reflecting to obtain consistent implications (Tsai, Shih \& Li 2010).

Table 1. Data collection and sources

\begin{tabular}{lll}
\hline Data sources & Episodes & Narrative materials \\
\hline $\begin{array}{l}\text { Part 1: } \\
\begin{array}{l}\text { The researcher interviews the } \\
\text { narrator and discusses with him }\end{array}\end{array}$ & $\begin{array}{l}\text { Eight episodes in the period from } \\
\text { June to October, 2019 with each } \\
\text { lasting for 2-2.5 hours }\end{array}$ & $\begin{array}{l}\text { 1. } \\
\text { The experiences as a business } \\
\text { manager }\end{array}$ \\
& & $\begin{array}{l}\text { 2. } \\
\text { The envisions for business } \\
\text { management }\end{array}$ \\
& $\begin{array}{l}\text { 3. Combination and use of } \\
\text { resources }\end{array}$ \\
\hline $\begin{array}{l}\text { Part 2: } \\
\text { Recordings from shadowing }\end{array}$ & $\begin{array}{l}\text { Four episodes in the period from } \\
\text { November 2019 to January 2020 } \\
\text { with each lasting for 6 hours }\end{array}$ & $\begin{array}{l}\text { 1. Management of factory } \\
\text { businesses }\end{array}$ \\
& & 2. How to drive changes in daily \\
& & businesses \\
\hline
\end{tabular}

\subsection{Analytical framework}

Based on the literature review, the analytical framework of this paper mainly comprises three concepts: the absorptive capacity of knowledge, bricolage, and value-creation (Figure 1). The absorptive capacity of knowledge is defined as 'the ability of a firm to recognize the value of new, external information, assimilate it, and apply it to commercial ends.' Bricolage refers to 'applying combinations of the resources at hand to new problems and opportunities.' Value-creation means creating or presenting diversified types of values through combination of resources.

Following Tsai, Shih and Li (2010) and Pentland (1999), five key features of narrative text can be identified for the analytical framework: (1) Events. They shall be included in the narrative in a certain structure. They are rearranged according to the need of the story, not necessarily in chronological sequence. (2) Focal actor or actors. Narratives are about some key characters that 'provide a thread that ties the events in a narrative together.' (3) 'Identifiable narrative voice. A narrative is something that someone tells,' 'so there should always be an identifiable voice doing the narrating.' (4) 'Evaluative frame of reference. Narratives carry meaning and cultural value because they encode ... standards against which actions of the characters can be judged.' (5) 'Other indicators of content and context.' For example, 'attributes of the context,' attributes of the narrator, and attributes of the listener, may be essential to the interpretation of the narratives.

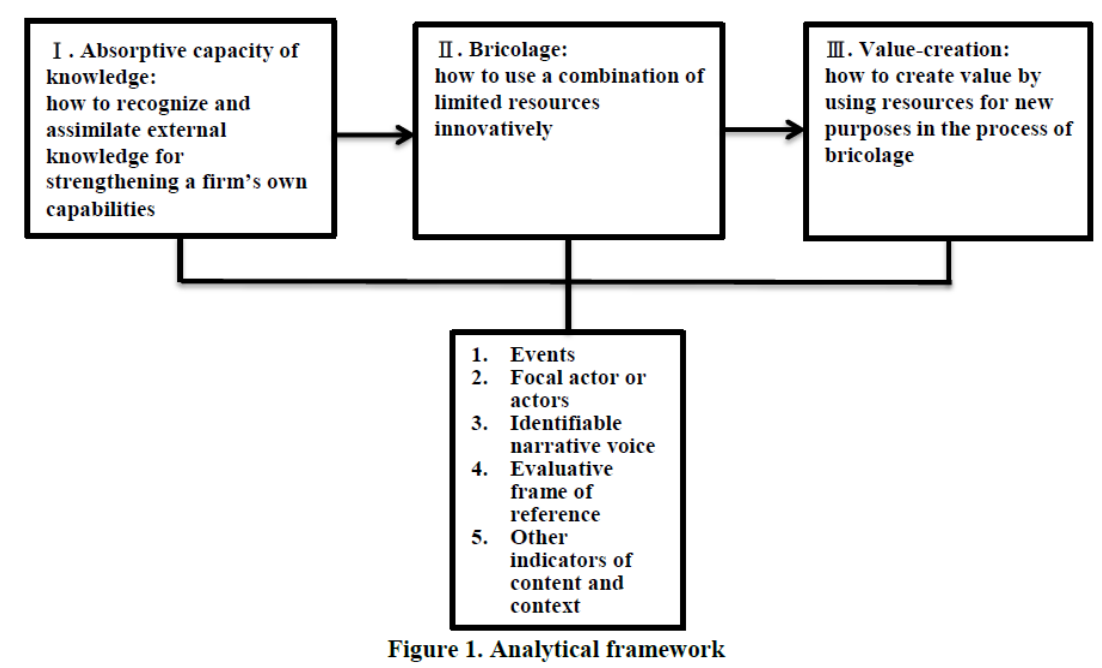




\subsection{Case overview}

The rubber industry is indispensable to economic development. The industry is also demanding in terms of know-how. C-C Rubber, which was established in January 1972, is a dominant and specialized manufacturer of industrial rubber in Taiwan. The rubber products, such as rubber fenders, bearing pads, protective traffic piles, slab crossings, insulation pads, and various shock-resistant rubber products, are widely used in the transportation industry, particularly, sea and road transportation infrastructures (for example, sea and river ports, noise and shock absorbing or resisting applications for railroads and bridge piers). Sales destinations of the products include Taiwan, Japan, South-east Asia, and Mainland China. In the past, industrial rubber products in Taiwan were manufactured according to traditional processes. There were few technological exchanges on topics such as formula design, die development, vulcanization system control, fluxing techniques, adhesion techniques, and emerging processes. With limited industrial knowledge and techniques, it was challenging for rubber businesses to acquire new resources. They had to rely on contracted manufacturing based on Japanese technologies for developing talents and own process technologies over a long time. C-C Rubber, as one of the largest rubber manufacturers in Taiwan, has been improving its production technologies continuously while optimizing the production process and the quality control system. It focused its efforts on developing and designing rubber fenders used in sea and river ports. The fenders are critical to port safety. Other company products also play an essential role in ensuring personal and project safety and facilitating the development of national infrastructures. With continuous efforts in staff development and comprehensive quality management, the company aims at providing consistent product quality and fulfilling its corporate responsibility in safeguarding public interests through excellent design, quality, after-sales service, and safety performance.

\section{Story analysis}

\subsection{Story 1: the original intention of contributing to national water conservancy programs}

The narrator graduated from the Department of Harbor \& River Engineering, National Taiwan Ocean University. He has an aspiration to contribute to national water conservancy programs. After being offered a job by C-C Rubber Company, he left his hometown in northern Taiwan and moved to the south, expecting that his knowledge and skills could be brought to full play in serving the company. However, he soon found that the company operated in a traditional industry. Under the difficulties of a constrained knowledge base and a closed technological environment, experienced technicians helped the company in fulfilling contracted orders with their experiences and skills accumulated in more than two to three decades. They could not explain the underlying knowledge of each process. Even for things that they could explain, they were unwilling to do so out of fear that they might lose their relevance when someone else learns the tricks. The narrator understood very well what he should do as a business manager under the circumstances. He recalls:

Twenty-five years ago, the company introduced rubber products manufacturing technology from Japan.

The formula was bought earlier on. The final products were the results of several stages in the manufacturing process, including fluxing, adhesion, vulcanization, and molding. The experienced technicians could explain how to manufacture but could not provide underlying explanations. The industrial knowledge base in the company was very narrow. Therefore, as conditions about cost, quality, and lead time changed under different market competitive landscapes, such a knowledge base could not meet market demands and led to substantial negative impact. With a science and engineering background, I am familiar with the applications of rubber fenders. However, I do not have a clear idea of the complex process in which rubber materials (such as natural rubber, synthetic rubber, and carbon black, etc.) are fluxed with other materials. Precisely, the Company as a whole lacks such knowledge. The knowledge about the applications of rubber polymers then was minimal and accessible to only a few people. I had to buy Japanese books on applications of synthetic rubber materials (I started the journey of learning Japanese for reading the books). At that time in Taiwan, there was no book on rubber formulas. Some books dealt with rubber for tires, but none of them addressed the application of rubber fenders. Also, they only provided basic formulas, which could not be used in the manufacturing process. To understand product technologies in the industry, I had to learn from the outside. I participated in the courses organized by rubber associations and research and development centers. The courses covered topics such as formula design, applications of polymers, fluxing and mastication, vulcanization system control, etc. Most importantly, the courses provided opportunities to engage with technical directors or business owners of different rubber-related products to build an extensive social network.

The narrator tried to learn to accumulate knowledge from the outside due to a shortage of internal technical knowledge resources. However, external courses dealt with only fundamental concepts, which could not quickly help the company in practical business operations. On the other hand, engaging with business owners, technical supervisors, or material suppliers for different products from related industries could provide useful knowledge. It could relieve technological constraints immediately. 
So, it was the right way to improve the situation. He goes on to say, Exchanging knowledge with external sources, including raising questions to each other and providing their solutions, is very instrumental to the building of an internal knowledge base. For example, in terms of mastication, traditional internal practice does not try to break the molecular chains through mastication. With long molecular chains, the fluxing process cannot distribute the reinforcing agent (carbon black) evenly and often leads to clouds of dust spreading.

Reduced reinforcing effects and longer fluxing time also cause an inconsistent distribution of molecular weight, imposing detrimental effects on product quality and production efficiency. We tested the mastication time of natural rubber by segmenting the period for identifying the differences between its Mooney viscosities. The exercise aimed at finding the most suitable processing time for the required physical property and vulcanization molding from the fluxing conditions. It improved production efficiency and product profitability. The knowledge was imported through external engagement. Although other companies may manufacture different products, there were similarities in the rubber process. Large tire plants, rubber conveyor belt manufacturers, or special compounding plants were particularly helpful. The polymer material knowledge accumulated by learning from outside continuously, product experiments, and exchanging information with external industries, helped the company in building the internal knowledge base on rubber fenders and in improving competitiveness.

The narrator graduated from the Department of Harbor \& River Engineering, National Taiwan Ocean University. With the aspiration of contributing to Taiwan's water conservancy programs, he was dedicated to the development and design of rubber fenders. After identifying the shortage of internal industrial knowledge and technological bottlenecks, which limited the Company's manufacturing capability in meeting market competition, he embarked on a journey of active learning and sourcing external knowledge. The external knowledge was accumulated selectively and used in building an internal knowledge base and in expanding applications. The knowledge helped in improving processing capacity, and in turn, in improving the Company's competition conditions. From this story, this study finds that self-awareness provides certain stimulation and inspiration for actions in the specific context of history and experiences. The result demonstrates that an individual's past experiences and words can be combined to form an interpretation (Tsai, Shih \& Li 2010).

\subsection{Story 2: Driving innovation with limited resources}

Bricolage stresses an attitude of refusing to be constrained, including not being constrained by the self-imposed framework and external forces. The constraints may be limited resources, those imposed by systems of organization, such as policies and provisions, or by a conceptual or intellectual framework (Domenico, Haugh\& Tracey 2010; Baker \& Nelson 2005). Sanchez-Burks, Karlesky and Lee (2015) define psychological bricolage as the process in which an individual combines prior irrelevant knowledge innovatively to identify new ways to solve problems. The narrator recalls:

SMBs in traditional industries lack resources such as machinery, equipment, funding, and human resources. They must use their resources effectively in facing challenges or constraints. Knowledge plays a critical role here. Applying different knowledge to the same resources may lead to different outcomes. We used to believe that raw materials are resources. Instead, money is the resource as we can acquire raw materials from suppliers in the market. Business competitive advantages depend on how these materials are turned into resources. The premise is that you must know how to connect the applications of the materials and work out a feasible blueprint. Continuous learning helps in understanding new applications. Together with data accumulated from product experiments, we could identify more opportunities in the innovative use of resources.

Management guru Peter F. Drucker, in his book Innovation and Entrepreneurship, suggests that 'there is no such thing as a resource until man finds a use for something in nature and thus endows it with economic value.' Innovation is to change the output of resources and systematically create different values and satisfaction. It is also trying to convert materials into resources and providing a new and more productive structure that combines existing resources. According to the literature on entrepreneurial opportunities, entrepreneurs must be keenly aware of opportunities in the face of difficulties. They must find opportunities for innovation in cross-disciplinary structures by their previously accumulated knowledge, technology, contacts, or special status in social networks (Hsiao, Ou\& Su 2017; Minniti 2004; Shane 2000). The narrator understands that his company's resources are scarce. In facing the challenges or constraints, prior knowledge must be used to making do of various raw materials in his mind to work out a feasible archetype. This is how opportunities for innovative use of resources are generated. An important external opportunity for innovation is to combine new knowledge with prior knowledge for better use of the resources. This involves dialog with the resource materials, turning back to their previous uses, and evaluating their availability. The narrator recalls

For example, when we started with the same blocks or legos, there were several pictures attached for possible products. They told you how to complete the work according to instructions, so everyone was on level ground. Over time, we can achieve something not on the pictures. 
Why? Our knowledge has changed, we are more familiar with these building blocks, and we can create different works with the same components. This also goes for a company, for which the blocks are materials and the picture represents constraints. Without the knowledge for innovation, all you can do is to produce the same products without a competitive edge. You have no way of knowing other innovations and breakthroughs in using the materials. In essence, this is 'elements are recognized for future use.' The ability to recognize relates to learning and individual development, which determines what outcomes will be produced from using limited resources.

In this story, it can be observed that the narrator would not restrict himself in the face of insufficient resources. He tried to remove the constraints by the innovative use of resources. By continuously learning new external knowledge and by combining it with existing knowledge, he managed to expand his knowledge base. Accumulation of knowledge helped in the identification of opportunities in the innovative use of resources. When the narrator was more familiar with available materials and could turn back to their previous uses and understand their availability, he could remove the constraints faced by his company. In shadowing observation, this study found that the narrator kept trying to simulate and adjust possible solutions in daily operation. The efforts helped in breaking down complex businesses into workable processes. In a changing environment, most of the management knowledge and skills are obtained in the process of business management through continuous exploration and adjustment of prior experiences (Gorman, Hanlon, \& King, 1997).

\subsection{Story 3: Determined to reform for creating value}

Innovation is often a purposeful organizational behavior, not a sudden emergence from human creativity. It is a systematic process for the more effective operation of resources to create value. Innovation, in essence, involves creating new value through the combination of technologies, market knowledge, and other products, services, or the entire business model operation. The narrator recalls:

At a high-level meeting more than ten years ago, we were discussing how to cope with a crisis. The financial crisis in 2008 caused rising prices of raw materials. Natural rubber prices jumped from $\$ 1$ to $\$ 5$ per kilogram with a supply shortage. Demands from listed and large tire plants and conveyor belt manufacturers were met first at more favorable prices. The surging price drove many businesses on the industrial chain to the point of being profitless or being at a loss, with many of them filing for bankruptcy. Given the fact that many of our clients were government agencies (such as Taiwan Port and Taiwan Railways Administration), we had to compete in bidding with others in terms of prices. The focus of the meeting was on how to overcome operational difficulties by preventing the waste of resources. I proposed organizational change and the adoption of the innovative production process.

However, all the shareholders and management present in the meeting could not understand because the older generation lacked such knowledge. I remembered that when I was proposing the program and talking about change, and then there was silence. A few seconds later, all of a sudden, there was a lot of excitement and accusations that I was going to defect? I'm like, oh my god! Change is mutiny ([one] cannot believe it). After a while of disorder, I continued with my essential proposal. Alas! The operating disadvantage of traditional industries was that they do not seek new knowledge or new technological breakthrough and innovation. Instead, they relied on the experiences accumulated in the past 20-30 years. They were always helpless in the face of changes in the environment (with a helpless sigh), and the special industry environment made people too comfortable.

According to the narratives, the study finds that prior successful experiences cause previous concepts and beliefs to be hard to change. With limitations in views, knowledge, and understanding, they fail to interpret the implications of these successes. Opportunities for improving internal organization and expanding external markets are missed or could not be identified due to a lack of knowledge. It is also possible that they are unwilling to support changes. Because relying on the technology or business model of the past 20 to 30 has made the company profitable. There is no substantial need for innovation in the face of market competition and environmental changes. Understandably, someone would feel helpless while confronting significant changes or fear and anger about the introduction of new knowledge. The narrator continuously recalls this process:

Fortunately, although we were an SMB with fewer resources, we were equipped with elasticity and responsiveness. After the consensus was reached, the execution efficiency and the effect was not too bad. In terms of organizational structure, five departments are simplified into three departments, with each department divided into two groups. On communication and coordination, improved timeliness and collaboration improve business management. We also introduced changes to the production process. Thanks to external knowledge and networking with many tire giant business owners, technological directors, and raw material suppliers, as well as continuous experiments and tests, we can recombine raw materials into new resources to develop and design new formulas. These efforts reform the whole production model, reduce production costs, and improve production efficiency and quality. To make full use of the existing resources, the company must identify their potential and use them flexibly. Otherwise, it is impossible to create value for itself. 
From this story, the study finds that the narrator can make do with his own resources by absorbing external knowledge (such as the practices of other businesses) in the face of difficulties and limitations. The efforts bring the innovative process to the company. It is also evident that the process cannot be structured innovatively merely by imitating the operation of others. Experiments, exploration, and adjustment are needed as re-interpretation for possible applications. The narrator is dedicated to his industry and is very familiar with the whole operations as well as the problems and deficiencies of the company.

Through continuous initiatives, learning, and absorption of external knowledge, he understood beforehand what was needed in terms of organizational innovations to improve operational efficiency. He knew where changes were needed to upgrade process capacity. These are the representations at the first layer. The practice and the application of knowledge is the second layer of representation.

The second layer of representation means that the story becomes structured after interpretation (Tsai, Shih \& $\mathrm{Li}$ 2010). For example, the black smoke in the sky, the honking of the fire engine, the noisy sound of the crowd, etc., are the superficial representation before understanding. When they are separated from each other, no meaning can be extracted from them. 'We saw the sky filled with black smoke, heard the rapid honking of the fire engine, and a group of people gathered in a panic to discuss the smoke.' With this description, the researcher interprets the previous understanding with the plot as the experience of a fire. The process is the representation in the second layer. The narrator has been dedicated to the development and design of the formula for rubber fenders for protecting piers or ships for nearly 30 years. He built his industry knowledge and technology base in the processes of manufacturing and experiments. He presented the process of value-creation by creating value for the company by removing resource constraints and innovatively changing the traditional manufacturing processes and the model of business management. This is the representation in the third layer through continuous adjustment and re-interpretation by the narrator (Tsai, Shih \& Li, 2010).

\section{Conclusions}

From the perspective of entrepreneurship, innovations by the actor in daily life are the processes that evolve without planning according to the context (Tsai, Shih \& Li 2010). In the first story, the narrator contributed to an industry with a state that deviated substantially from his expectations. Facing the reality of insufficient internal knowledge and technological bottlenecks, he embarked on a journey of active learning and sourcing external knowledge. The external knowledge was accumulated selectively and used in building an internal knowledge base and in expanding applications. The behavior represents self-awareness from the narrator's reflection.

Such self-awareness helps the study to understand outcomes from human self-awareness aroused by problems in daily life from the perspective of entrepreneurship. It also explains the mechanism through which self-identity is generating the need for self-expression, which in turn, creates the force to overcome difficulties and problems. In the second story, with a combination of external knowledge and prior knowledge and experiences, the narrator could look retrospectively at the resources and feel more comfortable with their availability. In the process of dialog with the materials, he bricolages in his mind based on his intellectual experiences. By identifying opportunities to use the resources innovatively and solutions to corresponding problems or constraints, he can make do with the resources at hand to recombine them and remove resource constraints. The researcher finds that in a changing environment, active learning and self-dialog to repeat the process of retaining the useful while deleting the inappropriate resources can help in meeting various limitations and problems.

In the third story, the narrator reformed the organizational structure and production processes in confronting global impacts. The internal objections to the reform initiatives can be attributed to a unique industrial environment, which did not readily accept new knowledge. The disagreements complicated the external shocks. The narrator developed a different view for his company in active learning (which expanded his visions) and routine interaction with various industries. He re-interpreted the company's resource structure through practices, actions, and learning. By contextualizing his situation more broadly, together with interdisciplinary interactions and brainstorming different professional views, he could reform and realize the value of the company by considering its features.

Through the narrated story, the study gained insights through the processes experienced in the case study.

(1) Self-awareness triggered by difficulties and constraints is the key to initiate knowledge innovation actions.

(2) Unique action and learning experience provide the basis for putting the theory of bricolage into practice.

(3) Re-interpretation in multiple contexts helps in value-creation by reforming processes.

In conclusion, if entrepreneurship and innovation can be deemed as capabilities that can be developed by learning, the process may involve building self-identity, recognizing resource constraints, facing various problems and difficulties, developing capacity for bricolage in the difficulties, and improving entrepreneurship and innovation under the stimulation of diversified contexts. 


\section{Acknowledgment}

This study could not have been completed successfully without the engagement and support of Director Yang.

\section{References}

An, W., Zhao, X., Cao, Z., Zhang, J., \& Liu, H., (2018). How Bricolage Drives Corporate Entrepreneurship : The Roles of Opportunity Ldentification and Learning Orientation, Product Development and Management Association, 35(1), 49-65.

Arksey, H., \& Knight, P., (1999). Interviewing for Social Scientists: An Introductory Resource with Examples. Thousand Oaks, CA: Sage Publication, Inc.

Baker, T., \&Nelson, R. E., (2005).Creating something from nothing: resource construction through entrepreneurial bricolage.Administrative Science Quarterly, 50(3), 329-366.

Bowman, C., \&Ambrosini, V., (2000). Value creation versus value capture: Towards a coherent definition of value in strategy. British Journal of Management, 11(1), 1-15.

Chen, Y. W., Wu, S. H.,\& Hsiang, W. H., (2010).The Resource-based View of the Resource Bricolage and Value Creation for the Innovative Product Development: A Case of Taiwan Opens Up the Wings. Journal of Technology Management, 15(2), 1-20.

Chesbrough, H. W., (2003). The Era of Open Innovation, Sloan Management Review, 44(3), 35-41.

Chesbrough, H. W., (2010). Business Model Innovation: Opportunities and Barriers. Long Range Planning, 43(2-3), 354-363.

Clandinin, D. J., \& Connelly, F. M., (2000). Narrative inquiry: Experience and story in qualitative research. San Francisco, CA: Jossey-Bass.

Cohen, W. M.,\&Levinthal, D. A., (1990). Absorptive Capacity: A New Perspective on Learning and Innovation, Administrative Science Quarterly, 35(1), 1128-1152.

Creswell, J. W., (1998). Qualitative Inquiry and Research Design: Choosing Among Five. Thousand Oaks, CA: Sage publications.

Creswell, J. W., \& Clark, V. L. P., (2007).Designing and Conducting Mixed Methods Research. Thousand Oaks, CA: Sage publications, Inc.

Cunha, M. P., (2005), Bricolage in organizations. FUENL Working Paper Series, No 474, Universidad Nova de Lisboa, Faculdada de Economia, (Available at SSRN: http://ssrn.com/abstract=882784)

Di Domenico, M., Haugh, H., \& Tracey, P., (2010). Social bricolage: Theorizing social value creation in social enterprises. Entrepreneurship theory and practice, 34(4), 681-703.

Duymedjian, R. \&Rüling, C. C., (2010). Towards a Foundation of Bricolage in Organization and Management Theory.Organization Studies, 31( 2), 133-151.

Eisenhardt, K. M., \& Martin, J. A., (2000).Dynamic Capabilities: What are they ?StrategicManagement Journal, 21(10/11), 1105-1121.

Garud, R. \&Karnøe, P., (2003). Bricolage versus Breakthrough: Distributed and Embedded Agency in Technology Entrepreneurship, Research Policy, 32(2), 277-300.

Gartner, W. B., (2007). Entrepreneurial Narrative and a Science of the Imagination. Journal of Business Venturing, 22(5), 613-627. 
Glucksberg, S., \&Danks, J. H., (1968), Effects of discriminative labels and of nonsense labels upon availability of novel function. Journal of Verbal Learning \& Verbal Behavior, 7(1), 72-76.

Gorman, G., Hanlon, D., \& King W., (1997). Some research perspectives on entrepreneurial education, enterprise education, and education for small business management: A ten year review. International Small Business Journal, 15(3), 56-77.

Hsiao, R. L., Ou, S. H., \& Su, Y. (2017). Inversing the powerful: process of resource construction through bricolage. NTU Management Review, 27(4), 1-32.

Hsiao, R., L., Ou, S. H., \& Wu, Y. K. (2017). Making-do within adversity: resource constraints as a source of innovation. Sun Yat-Sen Management Review, 25(1), 219-268.

Karim, S., \& Mitchell, W., (2000).Path-dependence and Path-breaking Change: Reconfiguring Business Resources Following Acquisition in the US Medical Sector 1978-1995. Strategic Management Journal, 21(10/11), 1017-1041.

Kraaijenbrink, J., Spender,J-C., \&Groen, A., (2010). The Resource-Based View: A Review of and Assessment of Its Critiques, Journal of Management, 36(1), 349-372.

Lennerfors, T., T.,\& Rehn, A., (2014). Chance Interventions - On Bricolage and the State As an Entrepreneur in a Declining Industry, Culture and Organization, 20(5), 377-391.

Lévi-Strauss, C., (1966), The savage mind (La penséesuavage), London: Weidenfeld\&Niolson.

Lin, T. C., Liou, Y. C., \& Liu, Y. C., (2007).An Investigation on Affecting Factors of Abilities of Mastering Entrepreneurial Opportunity: Using Social Capital Theory. Journal of Information Management, 14(3), 197-228.

Minniti, M., (2004), Entrepreneurial alertness and asymmetric information in a spin-glass model.Journal of Business Venturing, 19(5), 637-658.

Ou, S. H., (2015). Summoning resources from a deep sleep: business model innovation underlying 'lady first'. Sun Yat-Sen Management Review, 23(1), 225-267.

Pentland B. T., (1999). Building process theory with narrative: Form description to explanation. Academy of Management Review, 24 (4), 711-724.

Rubin, H. J., \& Rubin, I. S., (1995).Qualitative Interviewing: The Art of Hearing Data. Thousand Oaks, CA: Sage Publications, Inc.

Sanchez Burks, J., Karlesky, M. J., \& Lee, F., (2015). Psychological Bricolage: Integrating Social Identities to Produce Creative Solutions. The Oxford Handbo ok of Creativity,Innovation, and Entrepreneurship.

Senyard, J., Baker, T., Steffens, P., \&Davidsson, P., (2014).Bricolage as a path to innovativeness for resource-constrained new firms. Journal of Product Innovation Management, 31(2), 211-230.

Shane, S., (2000), Prior knowledge and the discovery of entrepreneurial opportunities.Organization Science, 11(4), 448-469.

Steyaert, C., (2004). The prosaics of entrepreneurship.In D. Hjorth\& C. Steyaert (Eds.), Narrative and discursive approaches in entrepreneurship (pp. 8-21).Chelthnham, UK: Edward Elgar.

Teece, D. J., Pisano, G. P., \&Shuen, A., (1997). Dynamic Capabilities and Strategic Management. Strategic Management Journal, 18(7), 509-533. 
Teece, D. J., (2007). Explicating Dynamic Capabilities: The Nature and Micro-foundations of (Sustainable) Enterprise Performance,Strategic Management Journal. 28(13), 1319-1350.

Tsai, C. A., \& Liao, M. K., (2016).Examining Firms' Strategies for Competitive Advantages through Resource-based View and Dynamic Capability View under Different Environments.Management Review, 35(1), 47-72.

Tsai, D. H., Shih, C. C., \& Li, S. J., (2010). Narrating an Entrepreneurial Story: Awareness, Learning and Reinterpretation. Organization and Management, 3(2), 67-91.

Wilson, C., (2012), The Integrated Propulsion Strategy Theory: A Resources, Capabilities and Industrial Organization. Journal of Management Policy \& Practice, 13(5), 159-171.

\section{Excursus}
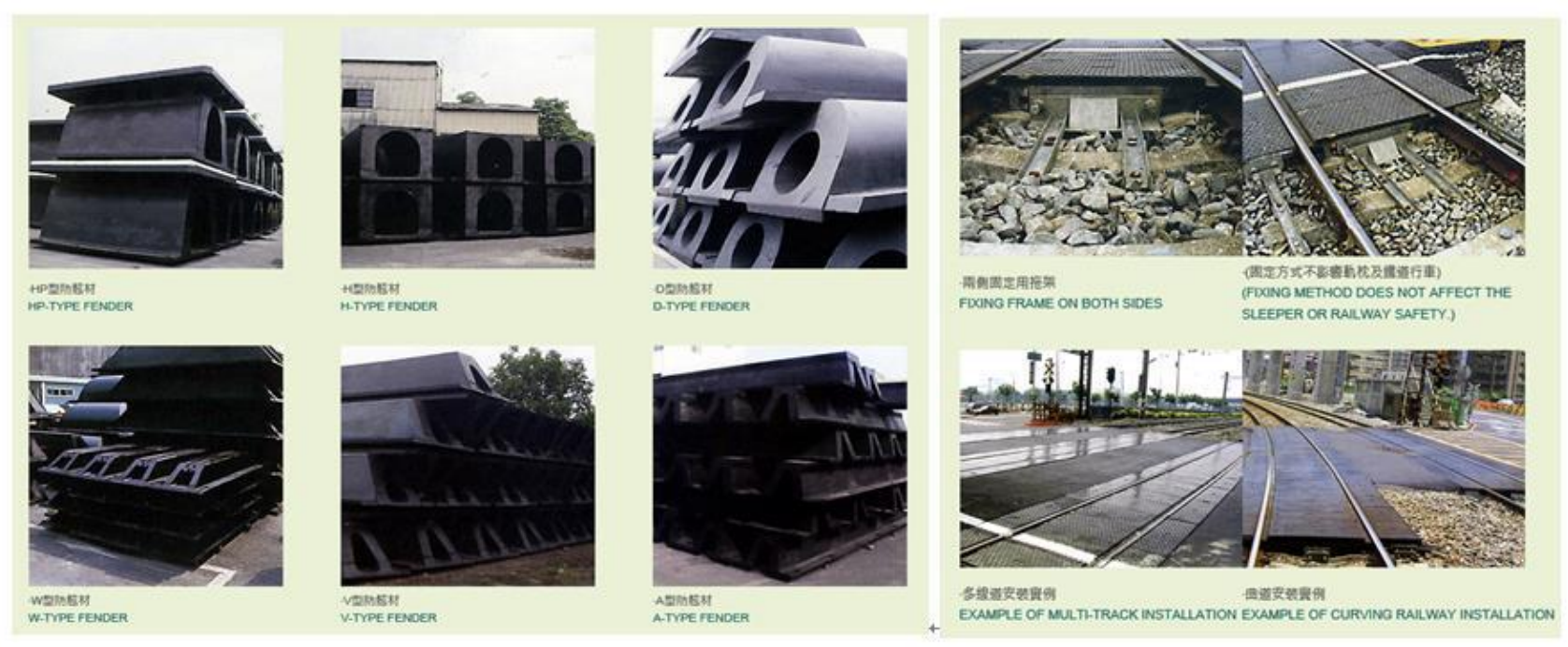

Data sources:Various forms of rubber fenders chih-cheng.com 